\title{
The Sucker Rod Pump Parameters Optimization of Horizontal Wells with ASP Flooding Considering the Influence of Centralizers
}

\author{
Zhen-Hai Jiang \\ No.3 Oil Production Plant, Daqing Oilfield Company, China
}

\begin{abstract}
The centralizers can add the polished rod load, and affect the pumping system efficiency. A pumping system efficiency model has been built by considering the influence of centralizers on polished rod load. The influence of centralizers, stroke length, pumping speed and flooding period on sucker rod pumping system efficiency and production has been studied. The results indicate that the sucker rod pumping system efficiency and production rate decrease while the number of centralizer increases, but the influence of number of centralizer on sucker rod pumping system efficiency and production rate is not big while the influence of stroke length and pumping speed is significant. The sucker rod pumping system efficiency first increase obviously and then trend to be gentle with the stroke length and pumping speed increasing. The pumping system efficiency in main slug of ASP flooding is lowest. The optimization value of stroke length and pumping speed has been selected to maximize the pumping system efficiency. And hence get the reasonable pump depth, and system efficiency, it have reference significance to the reasonable production.
\end{abstract}

\section{Introduction}

The viscosity of production fluid is high which can increase the eccentric wear between sucker rod and tubing [1], [2], so it is necessary to install centralizers on sucker rods, but the centralizers will increase the friction of the sucker rod and tubing and liquid column in the up and down stroke so it can add the polished rod load, and affect the pumping system efficiency [3], [4]. When the wells oil production is stable, the flow of the formation into wellbore is balanced with the actual flow of sucker rod pump, the different swabbing parameter of the sucker rod pump correspond different bottom hole producing pressure and production.

This paper studies the influence of centralizer and sucker rod pump parameters on the efficiency of the system efficiency. With the highest system efficiency as the goal, based on the pumping system efficiency calculation model, pumping system efficiency calculation model and the influence of various parameters on the system efficiency, the influence of centralizers, stroke length, pumping speed and flooding period on sucker rod pumping system efficiency and production has been studied. It has reference significance to the reasonable production.

\section{Pumping system efficiency calculation model}

Pumping system efficiency calculation model considering the influence of gas in the pump, volume change of the oil, pump leakage and stroke loss on pumping system efficiency.

When ASP flooding oil well produced fluid flow in the wellbore, it Performance for an emulsion of oil- gaswater three phases.

$$
\rho_{\mathrm{m}}=\frac{\left[\left(\rho_{\mathrm{o}}+R_{\mathrm{p}} \rho_{\mathrm{g}}\right)\left(1-f_{\mathrm{w}}\right)+\rho_{\mathrm{w}} f_{\mathrm{w}}\right]}{\left\{\left(1-f_{\mathrm{w}}\right)\left[B_{\mathrm{o}}+Z p_{\mathrm{sc}} T_{\mathrm{p}}\left(R_{\mathrm{p}}-R_{\mathrm{s}}\right) / p_{\mathrm{p}} T_{\mathrm{sc}}\right]+f_{\mathrm{w}}\right\}}
$$

ASP flooding produced liquid rheological model for power rate, the Reynolds number use generalized Reynolds number $\mathrm{Re}$ when liquid flow through the suction valve of oil well pump.

$$
\begin{aligned}
& \operatorname{Re}_{p l}=8^{1-n} \rho D^{n} v^{2-n} /\left\{k[(3 n+1) / 4 n]^{n}\right\} \\
& =8^{1-n} \rho D^{n} v^{2-n} /\left\{k[(6 n+2) / n]^{n}\right\}
\end{aligned}
$$

The viscosity of ASP liquid through the suction valve hole is given by:

$$
\mu=K \gamma^{n-1}
$$

Fluid through the pump suction valve hole flow pressure drop $\Delta_{p_{\text {in }}}$ is given by:

$$
\Delta p_{i n}=\rho_{m} v^{2} /\left(2 \xi^{2}\right)=\rho_{m} A_{p} v_{p}^{2} /\left(2 A_{v} \xi^{2}\right)
$$


The relation between the standardized valve flow coefficient and Re is given by:

$$
\begin{aligned}
& \xi=4 \times 10^{-22} \mathrm{Re}^{5}-2 \times 10^{-17} \mathrm{Re}^{4}-6 \times 10^{-13} \mathrm{Re}^{3} \\
& +6.5 \times 10^{-9} \mathrm{Re}^{2}+4.78 \times 10^{-5} \mathrm{Re}+0.0106
\end{aligned}
$$

$\Delta p_{\text {in }}$ is submergence pressure that in order to ensure the filled degree of pump, When fluid flows through the pump suction valve, pump pressure for gas is given by:

$$
p_{\mathrm{i}}=p_{s}-\Delta p_{\text {in }}
$$

Ratio of gas and liquid in the pump is:

$$
R=\left[Z T_{p} p_{s c} R_{p}\left(1-f_{w}\right)\left(1 / p_{i}-1 / p_{b}\right)\right] / T_{s c} B_{o}
$$

The influence of gas inside the pump on the pumping system efficiency is:

$$
\eta_{1}=1.1 /(1+R)-0.1
$$

The influence of oil volume change on the pumping system efficiency is [5]:

$$
\eta_{2}=1 /\left[B_{\mathrm{o}}\left(1-f_{\mathrm{w}}\right)+f_{\mathrm{w}}\right]
$$

The influence of pump leakage on the pumping system efficiency is approximately given by $[6,7]$ :

$$
\eta_{3}=\eta_{31} \eta_{32}=0.8924
$$

where, $\eta_{31}$ is space leakage between pump plunger and pump barrel, take 0.97 ; $\eta_{32}$ is valve leakage, take 0.92 .

The influence of stroke loss on the pumping system efficiency is [5]:

$$
\eta_{4}=1-\left(D_{p}^{2} \gamma_{1} L_{f} L / 2.62 \times 10^{11} S\right)\left(\sum_{i=1}^{n} a_{i} / f_{r i}+1 / f_{t}\right)
$$

The computational formula for pumping system efficiency is:

$$
\begin{aligned}
& \eta=\eta_{1} \eta_{2} \eta_{3} \eta_{4} \\
& =\left[\frac{1.1}{1+\left[Z T_{p} \rho_{m} g h_{s} R_{p}\left(1-f_{w}\right)\left(1 / p_{i}-1 / p_{b}\right)\right] / T_{s c} B_{o}}-0.1\right] \\
& \times 0.8924 /\left[B_{o}\left(1-f_{w}\right)+f_{w}\right] \\
& \times\left[1-\left(D_{p}^{2} \gamma_{1} L_{f} L / 2.62 \times 10^{11} S\right)\left(\sum_{i=1}^{n} a_{i} / f_{r i}+1 / f_{t}\right)\right]
\end{aligned}
$$

\section{System efficiency calculation model}

System efficiency calculation model is given by:

$$
\begin{aligned}
& \eta_{s}=p_{e} / p_{m i} \\
& =\frac{Q \cdot\left[h_{1}+\left(p_{o}-p_{c}\right) \times 1000 / \rho \cdot g\right] \cdot \rho \cdot g}{86400 \cdot p_{m i} \times 100 \%}
\end{aligned}
$$

$\mathrm{p}_{\mathrm{mi}}$ is associated with the load of pumping unit. The actual input maximum power of electrical machinery is given by:

$$
p_{m i}=0.81 M_{\max } n_{p} / 9549
$$

The computational formula for the maximum torque $\mathrm{N}_{\max }$ of crankshaft is:

$$
\begin{aligned}
& N_{\max }=1800 S \\
& +0.202 S\left[\rho_{\mathrm{s}} \mathrm{g} f_{\mathrm{r}} L+\rho_{1} g\left(f_{\mathrm{p}}-f_{\mathrm{r}}\right) L+I_{\mathrm{u}}\right. \\
& \left.+F_{\mathrm{u}}+p_{\mathrm{o}}-\left(\rho_{\mathrm{s}}-\rho_{1}\right) g f_{\mathrm{r}} L-I_{\mathrm{d}}-F_{\mathrm{d}}\right]
\end{aligned}
$$

$I_{u}, I_{d}$ is the maximum inertial load of sucker rod string and liquid column on up and down stroke, respectively.

$$
\begin{gathered}
I_{\mathrm{u}}=W_{\mathrm{r}}\left(S n_{p}^{2} / 1790\right)(1+\lambda) \\
I_{\mathrm{d}}=W_{\mathrm{r}}\left(S n_{p}^{2} / 1790\right)(1-\lambda)
\end{gathered}
$$

$F_{u}, F_{d}$ is the maximum friction load on up and down stroke, respectively.

$$
F_{\mathrm{u}}=F_{\mathrm{rt}}+F_{\mathrm{pb}}+F_{\mathrm{tl}}
$$

$$
\begin{aligned}
& F_{\mathrm{d}}=m \alpha 1.5 \% W_{\mathrm{r}}+F_{\mathrm{pb}} \\
& +2 \pi \mu L\left[\left(c^{2}-1\right) /\left[\left(c^{2}+1\right) \ln m-\left(c^{2}-1\right)\right]\right] v_{\max } \\
& +F_{\mathrm{cl}}+F_{\mathrm{v}} \\
& c^{\mu}=K\left[2\left(\pi S n_{p} / 60\right) /\left(d_{t}-d_{r}\right)\right]^{n-1}
\end{aligned}
$$

$F_{\mathrm{cl}}$ is the friction between the centralizer and liquid column which occur in the down stroke and the direction of friction is upward, when there is a centralizer, fluid flow through the centralizer will generate additional pressure drop due to the centralizer flow section is small, then the friction between centralizer and the fluid column is given by:

$$
\begin{gathered}
F_{\mathrm{cl}}=\Delta p_{\mathrm{h}} A_{\mathrm{c}} \\
\Delta p_{\mathrm{h}}=0.25 v_{\text {max }}^{2} A_{\mathrm{c}} / A_{\mathrm{p}}
\end{gathered}
$$

$F_{\mathrm{tl}}$ is the friction between liquid column and the tubing, it occur in the up stroke so increases suspension point load. Calculating formula is:

$$
F_{\mathrm{tl}}=\Delta p_{\mathrm{L}}\left(f_{\mathrm{t}}-f_{\mathrm{r}}\right)
$$

$F_{\mathrm{pb}}$ is the friction force between piston and liner which exist all the time. The value can be calculated according to the following formula: 


$$
F_{\mathrm{pb}}=0.94 d_{\mathrm{p}} / e-140
$$

$F_{\mathrm{v}}$ is the friction force of liquid through the floating valve, in the big production Wells with high viscosity, the resistance caused by the liquid through the floating valve is often the main reason for the bending of the sucker rod string, and the influence on the suspended load cannot be ignored. Calculation formula is given by:

$$
F_{\mathrm{v}}=\frac{1}{729}(S n)^{2} \rho_{1} \cdot f_{\mathrm{p}}^{3} /\left(\mu^{2} \cdot f_{\mathrm{o}}^{2}\right)
$$

\section{System efficiency influence factors}

The influence of centralizers, stroke length, pumping speed and flooding period on sucker rod pumping system efficiency show in Fig. 1- Fig. 4, respectively. The results indicate that the sucker rod pumping system efficiency decrease while the number of centralizer increases. The influence of stroke length and pumping speed on sucker rod pumping system efficiency is significant. The sucker rod pumping system efficiency increase obviously with the stroke length and pumping speed increasing, but while the stroke length is bigger than $5 \mathrm{~m}$ and pumping speed more than 6 min-1 it increase gently. In different displacement stage, due to viscosity of produced liquid is different, by force in the wellbore is different, so the system efficiency is also different, the pumping system efficiency in main slug of ASP flooding is lowest.

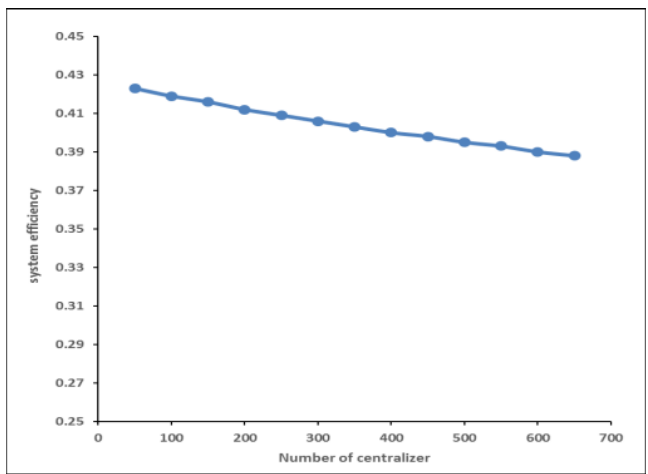

Figure 1. The influence of centralizers on sucker rod pumping system efficiency.

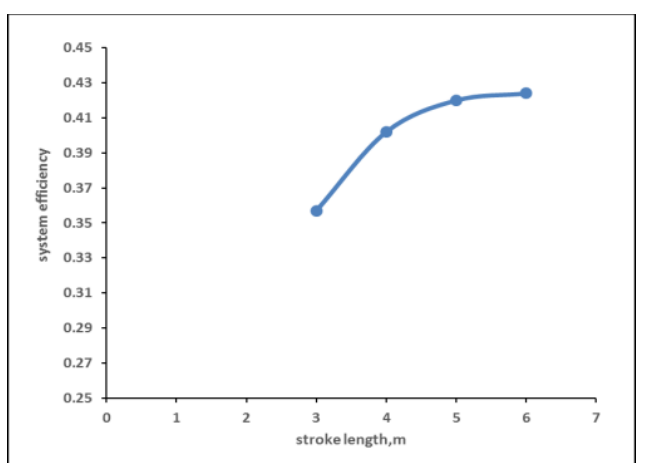

Figure 2. The influence of stroke length on sucker rod pumping system efficiency.

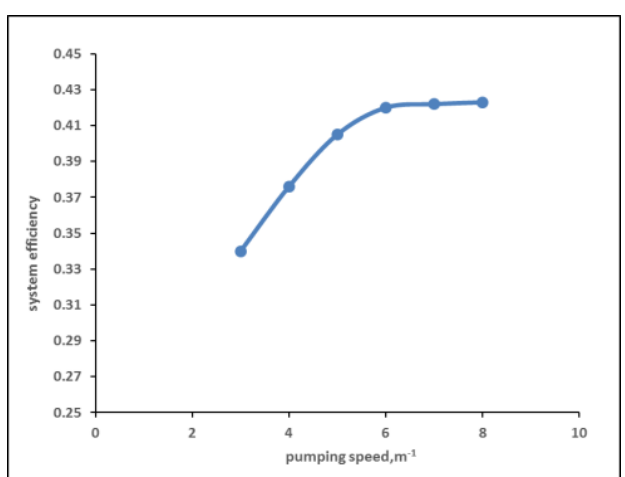

Figure 3. The influence of pumping speed on sucker rod pumping system efficiency.

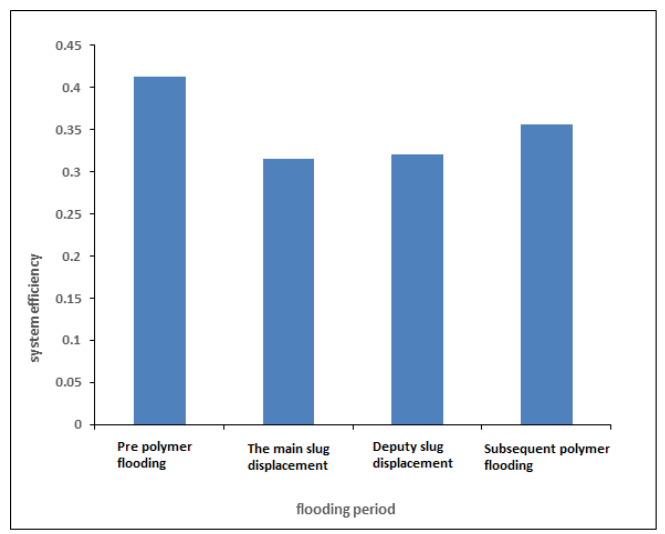

Figure 4. The influence of flooding period on sucker rod pumping system efficiency.

\section{Determination of the reasonable pump depth and system efficiency of ASP flooding}

The viscosity of production fluid is high which can make the condition complex of the wellbore. A low pump depth result in a low production of the oil well, on the contrary, the eccentric wear between sucker rod and tubing will be serious if pump depth is too high, so it is necessary for improve the well working condition, pumping system efficiency and production to get the reasonable pump depth.

According to the data of a production plant in Daqing, the optimization value of pump depth has been selected to maximize the pumping system efficiency. The biggest pump depth is $950 \mathrm{~m}$.

$$
\begin{gathered}
H_{\mathrm{m}}>0 \\
H_{\mathrm{f}}-\left(P_{\text {wf }}-P_{\mathrm{c}}\right) /\left(\rho_{\text {mix }} g\right)+H_{\text {pump }}<950
\end{gathered}
$$

The inflow performance relationship curve of produced wells is different in different displacement stage, therefore the system efficiency of different displacement stage is different, need to calculate the change law of bottom hole flowing pressure, production, system efficiency, and pump depth under the different displacement stage with different submergence depth of ASP flood. The stroke range for 3-6 m, speed range is 3-8 
times/min on the spot, get the optimization results of stroke, stroke times, bottom hole flowing pressure and pump depth under the different displacement stage with the maximum system efficiency of two kinds of pump diameter, as show in Table 1.

Table 1. Optimization results of pump depth and system efficiency under different flooding stages

\begin{tabular}{cccccc}
\hline Stage & Stroke[m] & $\begin{array}{c}\text { Sumber of } \\
\text { stroke[times/min] }\end{array}$ & $\begin{array}{c}\text { Pump } \\
\text { diameter[m] }\end{array}$ & $\begin{array}{c}\text { Sump } \\
\text { depth[m] }\end{array}$ & $\begin{array}{c}\text { System } \\
\text { efficiency[\%] }\end{array}$ \\
\hline $\begin{array}{c}\text { Water flooding } \\
\text { stage }\end{array}$ & 5 & 3 & 0.083 & 787 & 45.9 \\
Pre polymer & 5 & 4 & 0.07 & 764 & 44.7 \\
flooding & 6 & 6 & 0.083 & 629 & 31.8 \\
Main slug & 6 & 7 & 0.07 & 616 & 32.0 \\
Sub slug & 6 & 8 & 0.083 & 662 & 26.3 \\
$\begin{array}{c}\text { Subsequent } \\
\text { polymer flooding }\end{array}$ & 6 & 8 & 0.07 & 638 & 632 \\
\hline
\end{tabular}

\section{Conclusion}

(1) Asp flooding produced fluid viscosity is bigger, can produce a larger pressure drop in pump suction that affect the fluid level of pump and reduce the pump efficiency.

(2) The centralizer rubs with tubing and produced liquid can affect the suspension center load, and results in the decrease of system efficiency.

(3) when the submergence depth is too big, will cause the production is too high, bottom hole flowing pressure is too low, the depth of producing fluid level from well head is too big, result in pump depth more than deflection point. when the submergence depth is too small, will cause the production is too low, bottom hole flowing pressure is too high, producing fluid level reached the well head, we obtained the reasonable stroke, stroke times, bottom hole flowing pressure and pump depth under the different displacement stage with two kinds of pump diameter of ASP flooding.

$\mathrm{R}_{\mathrm{p}}$ - produced gas-oil rate, $\mathrm{m}^{3} / \mathrm{m}^{3}$;

$\mathrm{R}_{\mathrm{s}}$ - dissolved gas-oil ratio, $\mathrm{m}^{3} / \mathrm{m}^{3}$;

$\mathrm{T}_{\mathrm{sc}}$ - standard state temperature, $293 \mathrm{~K}$;

$\mathrm{T}_{\mathrm{p}}$ - flow temperature of Pump inlet, $\mathrm{K}$;

$\mathrm{P}_{\mathrm{p}}$ - pressure of Pump inlet, $\mathrm{Pa}$;

$\mathrm{D}$ - diameter of suction valve, $\mathrm{m}$;

$\xi$-valve flow coefficient;

$A_{p}, A_{v}$ - the area of plunger and valve port, respectively, $\mathrm{m}^{2}$;

$v_{\mathrm{p}}$ - the movement velocity of plunger, $\mathrm{m} / \mathrm{s}$.

$\mathrm{p}_{\mathrm{s}}$ - submergence pressure, $\mathrm{Pa}$.

$\mathrm{L}_{\mathrm{f}}$-working fluid level, $\mathrm{m}$;

$\mathrm{L}$ - the total length of sucker rod, m;

$\mathrm{f}_{\mathrm{t}}$ - the metallic cross-sectional area of tubing, $\mathrm{m}^{2}$;

ai-the ratio between the sucker rod and the total length; $\mathrm{f}_{\mathrm{ri}}$ - the cross-sectional area of sucker rod, $\mathrm{m}^{2}$;

$\mathrm{D}_{\mathrm{p}}$ - diameter of pump, m;

$\gamma_{1}$ - the specific gravity of liquid;

$\mathrm{S}$ - stroke, $\mathrm{m}$.

$\mathrm{P}_{\mathrm{e}}$ - available power, $\mathrm{kW}$;

$\mathrm{P}_{\mathrm{mi}}$ - the input power of electric motor, $\mathrm{kW}$;

$\mathrm{h}_{1}$ - the well working fluid level, $\mathrm{m}$;

$\mathrm{P}_{\mathrm{o}}$ - the well tubing head pressure, $\mathrm{MPa}$;

$\mathrm{P}_{\mathrm{c}}$ - the well surface casing pressure, $\mathrm{MPa}$.

$\mathrm{n}_{\mathrm{p}}$ - pumping speed, $\min ^{-1}$;

$\rho_{\mathrm{s}}$ - the density of rod material(steel);

$\mathrm{f}_{\mathrm{r}}$ - the cross-sectional area of sucker rod, $\mathrm{m}^{2}$;

$c$ _ the ratio of tubing inside diameter and sucker rod diameter, $\mathrm{m}$;

$\mathrm{A}_{\mathrm{c}}$ - the cross-section area of centralizer, $\mathrm{m}^{2}$;

$\Delta \mathrm{p}_{\mathrm{l}}$ - the frictional pressure drop of liquid in the annulus.

\section{References}

1. Wang Yan, Technology for Controlling Eccentric Wear of Sucker Rods and Tubing in Pumping Wells Lifting Fluids Containing Polymer, SPE 89927.

2. Hong-Sheng Han, Li-Ping Guo, Yu-wang Song, Effect of resistance in polymer flooding on sucker rob partial abrasion. Journal of Daqing Petroleum Institute, 27(4):21 25, (2003).

3. O.Rivas, A. Newsky, M. Cedeno, et al, Sucker Rod Centralizers for Directional Wells, SPE21131

4. Rui-Xia Zhang, Zeng-Liang Li, Dong Jiang, Study of Sucker Rod Centralizer Disposition of Reciprocal Sucker Rod Pump, Oil Field Equipment, 37(12):2835, (2008).

5. Hong-Tao Dong, Tao $\mathrm{Wu}, \mathrm{Qu}$ Liao, et al, Relationship between suitable submergence depth 
with pump efficiency, Inner Mongolia Chemical, 18: 36-39, (2010).

6. Qi-Biao Xia, Yong-Hui Liu, Xin-Fu Zhou, The frictional force calculation and the centralized distribution design of sucker rod string in directional wells, Drilling and Production Technology, 27(1): 60-63, (2004).

7. Ming-Qiang Zhao, Chao-Dong Tan, Fu-Qing Yang, Study of sucker rod centralizer optimized design research, 11: 51-53, (2012). 